\title{
Supporting design for remanufacturing - A framework for implementing information feedback from remanufacturing to product design
}

\section{Louise Lindkvist Haziri ${ }^{1}$ (D) Erik Sundin ${ }^{1}$}

Received: 30 January 2019 / Accepted: 13 August 2019 / Published online: 4 September 2019

(C) The Author(s) 2019, corrected publication 2019

\begin{abstract}
Remanufacturing is an industrial process turning used products into a condition of like new or better. Remanufacturing is also one strategy that salvages the value put into products during manufacturing and thus reduces the environmental impact of products over the life-cycle. However, not many products are designed for remanufacturing, and there is rarely any feedback from remanufacturing to design. Since design for remanufacturing is not applied at most manufacturing companies, there is a need to support companies, for example, by information feedback methods. By implementing feedback transfer from remanufacturing to design and employing design for remanufacturing, the remanufacturing process is more likely to be effective and efficient. The aim of this paper is to present a framework that supports design for remanufacturing by the implementation of structured feedback from remanufacturing to design. The framework aims at strategically outlining and practically implementing information feedback from remanufacturing to design. A case company where the framework has been initialised is also presented.
\end{abstract}

Keywords Remanufacturing · Case study · Design for remanufacturing · Product design · Circular design $\cdot$ Circular economy

\section{Introduction}

In a world focusing on consumption and economic growth, producers have an increasing impact on the welfare of our planet. Remanufacturing is one strategy that companies can apply in order to address and reduce the environmental impact of their products. Remanufacturing is an important component of a resource-efficient manufacturing industry [see, e.g. 3, 35, 37, 40]. Remanufacturing entails producers taking products back after use and restore them to a state

Louise Lindkvist Haziri

louise.lindkvist@liu.se

1 Division of Manufacturing Engineering, Department of Management and Engineering, Linköping University, 58183 Linköping, Sweden 
like-new, or better in an industrial process. By keeping components and their embodied material in use for a longer period, significant energy use and emissions to air and water (e.g., $\mathrm{CO}_{2}$ and $\mathrm{SO}_{2}$ ) can be avoided. According to Sundin and Lee [40], environmental comparisons of remanufacturing versus new manufacturing and/or material recycling show environmental benefits for remanufacturing. This is due to the alleviation of depletion of resources, reduction of global warming potential, and better chances to close the loop for safer handling of toxic materials [40]. In addition to its environmental benefits, remanufacturing provides opportunities for the creation of jobs as well as economic growth.

To achieve an effective remanufacturing process, product information should preferably be accessible for the remanufacturing personnel, and the products should be adapted for the remanufacturing process [39]. Although previous research [27] identified information that could be fed back to the design phase from remanufacturing (see Table 1), such information is not often available in the design phase [23].

Design for remanufacturing (DfRem) aims at facilitating the remanufacturing process by product design so that, e.g., disassembly, cleaning, reprocessing and reassembly are facilitated [38]. However, products are often not designed for remanufacture [15, 34, 38], although there do exist guidelines for DfRem [see, e.g., 3, 8] Further, Hatcher et al. [17] point out a gap in research regarding the operational factors influencing DfRem integration into the design process. In their findings, external factors such as customer demand and internal factors such as the relationship between the original equipment manufacturer (OEM) and remanufacturer were identified.

Communication between design and remanufacturing has the potential to lead to products that are more remanufacturable and a more efficient design process [14]. Many end-of-use $(\mathrm{EoU})$ issues preventing products and material from being salvaged stem from design; hence, it is most effective to incorporate EoU management considerations into the early product design stages. The OEM should adopt a system perspective in designing the product as a system solution. Considerations regarding features that facilitate the EoL processes are necessary. This is demonstrated in the case of single-use cameras by Kodak [5] and Fujifilm [41] where design changes led to an efficient and effective remanufacturing process. In the case of remanufacturing, one important criterion is that the parts that are to be replaced in repair and remanufacturing must withstand the treatment of being inspected, disassembled, cleaned, reprocessed, reassembled and tested several times [39].

Since DfRem is not applied at most manufacturing companies, although many currently conduct remanufacturing or have contracted remanufacturers [see, e.g., 8], there is a need of support methods to reach DfRem, e.g., information feedback methods. However, this study

Table 1 Potential sources of feedback from remanufacturing to design (adapted from Lindkvist and Sundin [27])

\begin{tabular}{|c|c|c|}
\hline Feedback sources & Feedback content & References \\
\hline $\begin{array}{c}\text { Remanufacturing } \\
\text { process data }\end{array}$ & $\begin{array}{l}\text { Evaluating how well the product was } \\
\text { adapted for efficient treatment in each } \\
\text { remanufacturing process step }\end{array}$ & $\begin{array}{l}\text { Doyle et al. (2011) [10]; Lee et al. (2006) } \\
\text { [24]; Hatcher et al. (2011) [15]; Zhang } \\
\text { et al. (2012) [45] }\end{array}$ \\
\hline $\begin{array}{l}\text { Remanufacturing } \\
\text { personnel data }\end{array}$ & Suggestions for improvement & Xu et al. (2009) [43]; Zhang et al. (2012) [45] \\
\hline $\begin{array}{l}\text { Cores to be } \\
\text { remanufactured }\end{array}$ & $\begin{array}{l}\text { Evaluating how well the } \\
\text { component was adapted for } \\
\text { its estimated life cycle }\end{array}$ & $\begin{array}{l}\text { Fathi and Holland (2009) [12]; Abramovici et } \\
\text { al. (2009) [2]; Abramovici and Linder } \\
\text { (2011) [1]; Dienst et al. (2011) [9]; Xu } \\
\text { et al. (2009) [43] }\end{array}$ \\
\hline
\end{tabular}


does not include independent remanufacturing companies, as the incentives for DfRem and information sharing in those cases are low for the OEMs. Further, OEMs have information about the design properties and possibilities to monitor products during the use phase. Consequently, OEMs are in a more favourable position than independent remanufacturers to administrate such information and enhance information exchange within the value chain.

Therefore, the proposed framework is directed at OEMs that include both design and remanufacturing in their operations and specifically supports the integration of information from remanufacturing into the design process in order to better adapt products for remanufacturing. With products designed for remanufacturing, the long-term goal is to improve the effectiveness and efficiency in the remanufacturing process.

\section{Aim}

The aim of this paper is to present a framework that supports design for remanufacturing by the stepwise implementation of strategies for information feedback from remanufacturing to design.

\section{Methodology}

In order to meet the aim of the paper, a literature review was performed to explore feedback from remanufacturing potentially useful in the product design process. The literature search used words including design information, information feedback, remanufacturing, product design and product development in the Science Direct and Google Scholar databases.

The empirical part of this study was based on data gained from interviewing remanufacturing managers, technicians, product designers, design managers and design project leaders. A single case study was carried out at a large international company; however, the focus of this study is the unit that designs and manufactures machines as well as a unit that remanufactures machines based in Sweden. This company group designs, manufactures, maintains, provides services and remanufactures machines. It has an established remanufacturing process, but no pronounced DfRem activities. Thus, the company was found suitable as a case within this research.

In this paper, the departments of design, manufacturing, service and remanufacturing will be presented in italics to differentiate them from the process of design and remanufacturing, etc.

\section{Design for remanufacturing}

When adapting products for remanufacturing, all the operation steps, e.g., inspection, disassembly, reprocess, reassembly and testing, need to be considered [39]. One should remember that the essential goal in remanufacturing is part reuse. Thus, if a part cannot be reused as is or after repair, the ease of cleaning or reassembly will have less value in terms of remanufacturing [44]. This means that much effort can be made in product design without obtaining the full expected benefits.

Many EoU issues preventing products and material from being salvaged stem from design; hence, it is most effective to incorporate the EoU management consideration into the early 
product design stages. The product developer should preferably adopt a system perspective in designing the product as a system solution. A decision support tool developed by Mangun and Thurston [31] was presented to help determine when products should be taken back as well as the most appropriate component end-of-life (EoL) options. Moreover, Amezquita et al. [4] developed guidelines based on design features that assist remanufacturing and used these to identify design changes to improve automobile door remanufacturability.

Furthermore, there are design guidelines developed for DfRem; see, e.g., Ijomah [18] and Allwood et al. [3]. In addition, Bras and Hammond [7] used the Boothroyd and Dewhurst design for assembly metrics [6] as a foundation to create remanufacturability assessment metrics based on product design features. Harjula et al. [13] contend that typical design changes according to design for assembly (DfA) methods will be equally beneficial in simplifying disassembly at the EoL stage. Furthermore, Harjula et al. [13] state that design for disassembly (DfD) changes that simplify the removal of critical items should also be considered. This is advantageous for products such as flat panel displays containing mercury back-lights [11]. This is also beneficial for small electrical products, where the batteries need to be removed easily for proper disposal and to preserve the value of the remaining materials for recovery purposes. However, remanufacturing of e-waste may be less suitable than recycling depending on the technical design, market factors and the efficiency of the recycling centres [16]. There are tools for DfEoL to aid in decision making at the EoL stage, e.g., ELDA [35] and DELII $[11,23]$.

In addition, Sundin and Bras [39] have studied which product properties are preferable for a product to have to facilitate remanufacturing. By looking at what properties are suitable for the different remanufacturing steps (inspection, cleaning, disassembly, storage, reprocess, reassembly and testing), a matrix called RemPro was created. The remanufacturing company should first investigate which steps are crucial for its specific remanufacturing business area and thereafter try to facilitate these steps by working to give their product the preferable properties according to the RemPro matrix (Table 2), as well as place effort on making the crucial steps in the remanufacturing process as efficient as possible.

The RemPro matrix then shows the designers which product property facilitates each remanufacturing process step. It does not, however, provide a method for reaching those product properties. To reach these essential product properties, Allwood et al. [3] have added design guidelines to complement the RemPro matrix.

Only products satisfying environmental legislation can be introduced into the market. Thus, DfRem guidelines must help to ensure that products can meet current environmental legislative

Table 2 The RemPro matrix, showing the relationship between the essential product properties and the generic remanufacturing process steps [39]

\begin{tabular}{|c|c|c|c|c|c|c|c|}
\hline $\begin{array}{l}\text { Remanufacturing step } \\
\text { Product property }\end{array}$ & Inspection & Cleaning & Disassembly & Storage & Reprocess & Reassembly & Testing \\
\hline Ease of Identification & $\mathrm{x}$ & & $\mathrm{x}$ & $\mathrm{x}$ & & & $\mathrm{x}$ \\
\hline Ease of Verification & $\mathrm{x}$ & & & & & & \\
\hline Ease of Access & $\mathrm{x}$ & $\mathrm{x}$ & $\mathrm{x}$ & & $\mathrm{x}$ & & $\mathrm{x}$ \\
\hline Ease of handling & & & $\mathrm{x}$ & $\mathrm{x}$ & $\mathrm{x}$ & $\mathrm{x}$ & \\
\hline Ease of separation & & & $\mathrm{x}$ & & $\mathrm{x}$ & & \\
\hline Ease of securing & & & & & & $\mathrm{x}$ & \\
\hline Ease of alignment & & & & & & $\mathrm{x}$ & \\
\hline Ease of stacking & & & & $\mathrm{x}$ & & & \\
\hline Wear resistance & & $\mathrm{x}$ & $\mathrm{x}$ & & $\mathrm{x}$ & $\mathrm{x}$ & \\
\hline
\end{tabular}


requirements and have at least good potential to satisfy future ones, either in their original design or because of their ease of redesign after their first life. Since products may have different types and levels of environmental impacts at different stages, DfRem guidelines must consider the whole life-cycle to target key environmental impact. Research by Ijomah et al. [18] indicates that there appears to be a lack of DfRem guidelines based on life-cycle thinking.

Furthermore, barriers and challenges for DfRem integration in the design process have been identified by Hatcher [14]. One barrier based on the organizational structures was that design and remanufacturing fail to see the advantages of increased communication as they lack insight into the respective processes [14]. Another barrier is the lack of incentives for design engineers to communicate with remanufacturing technicians [14]. Moreover, research by, e.g., Kurilova-Palasitenene et al. [22] shows that there is plenty of information within the products' life-cycles that can be used to achieve improved product designs and thus more efficient remanufacturing processes. However, several barriers to information sharing between remanufacturing and design have been identified [28] (Fig. 1).

Based on the lack of a structured approach to bridge the information gap between design and remanufacturing, a framework for implementing DfRem by the stepwise implementation of feedback from remanufacturing to design is presented below.

\section{The remanufacturing information feedback framework (RIFF)}

The Remanufacturing Information Feedback Framework (RIFF) is a method for strategically outlining and practically implementing feedback from remanufacturing to design. The framework is derived from both literature studies and empirical studies. The RIFF is based on back casting principles and consists of four steps (Fig. 2).

Firstly, the current situation is assessed in Step 1, and thereafter the future vision is outlined in Step 2. Step 3 provides actions for the stepwise implementation of feedback from

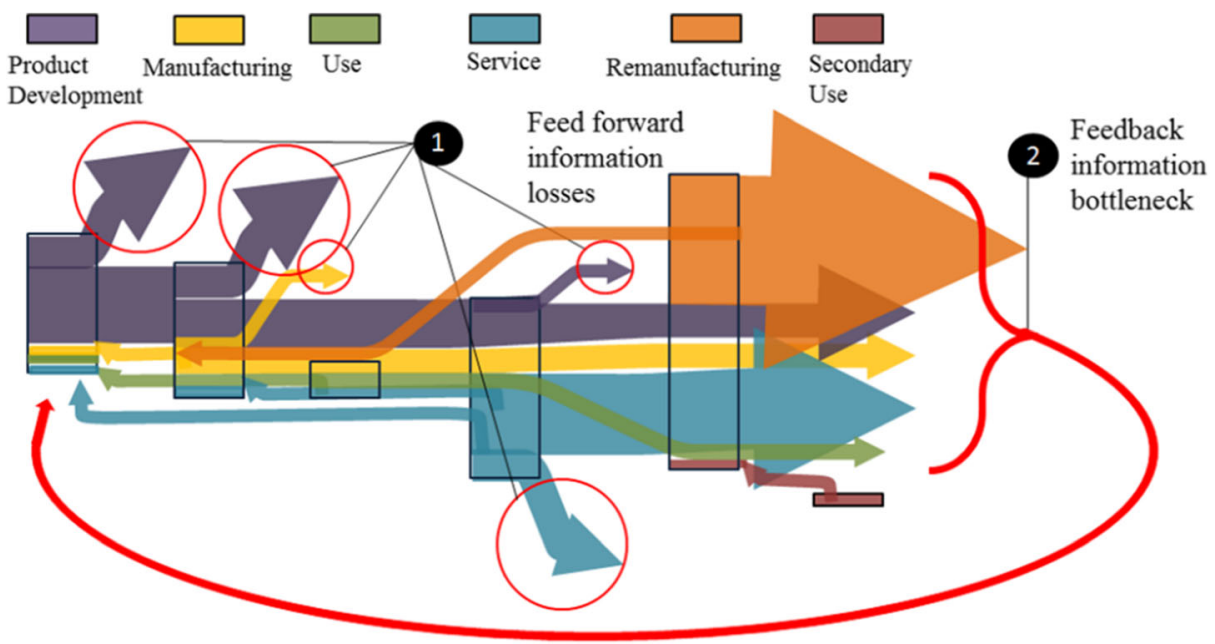

Fig. 1 A Sankey illustration showing a representation of product life-cycle information flows and the waste of information (1) among the product life-cycle stakeholders. Furthermore, a bottleneck for potential information feedback flows is highlighted (2). The width of the arrows represents the number of information categories, not the amount of information. Based on multiple cases studied by Kurilova-Palisaitiene et al. [22] 


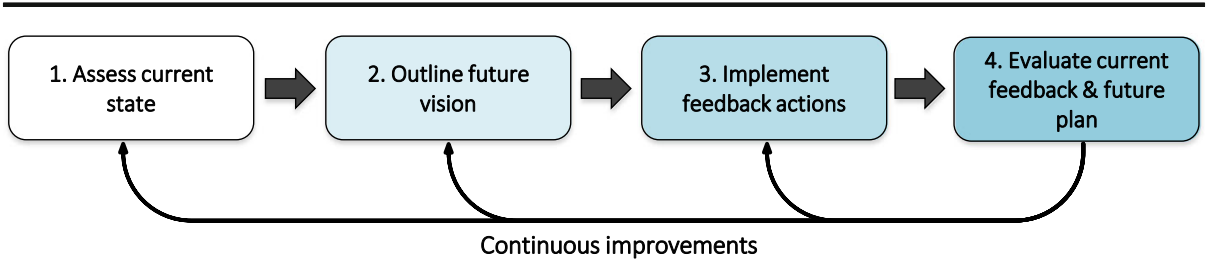

Fig. 2 The overall structure of the Remanufacturing Information Feedback Framework that supports the implementation of feedback from remanufacturing to product design by four successive steps. The method further encourages continuous improvements

remanufacturing to design. These actions are prioritized, and a time plan is created. The Identified first action is then carried out. The final step is an evaluation of the effects of the implemented actions and the effect that they have regarding DfRem. Further, Step 4 is also a checkpoint evaluating if the plan created in Step 3 needs revising or not. After that, the method steps are repeated until the vision is fulfilled (Table 4). The following sections will describe the steps in more detail.

\section{Step 1 - Assess current state}

Initially, the current situation regarding the information feedback flows is assessed. The assessment is conducted via interviews with stakeholders within design and remanufacturing, in this case, relevant staff within the product development department such as managers, design engineers, and project managers. Likewise, within the remanufacturing organization, managers and remanufacturing technicians may be interviewed. These individuals, representing one of the appointed stakeholders (e.g., project manager), should preferably be interviewed separately in order to obtain answers reflecting reality rather than what is, for example, accepted internally as policy.

The interview setup is based on getting input from design, manufacturing, service and remanufacturing regarding the information transfer. The outlook in many companies is that there is no information transfer from remanufacturing to design. Thus, the questions cannot solely focus on that subject but rather aim at painting a picture of what the information transfer looks like regarding the design process. It is important not only to see and visualise the information transfer process but indeed to verify the conditions for the information transfer. Although systems for information sharing and transfer are in place, the picture of what the information transfer looks like will probably vary a bit, depending on who is asked. Every department will have knowledge about its information flows, but in this step, the collective view is explored. It is important that the interviews are carried out by an unbiased person. The interviewees should feel compelled to freely answer the questions so that the answers reflect the real, and not the ideal, situation. It is also essential that the aim of the interview is clearly defined and that the respondent has received the information well before the interview so that he or she can prepare by thinking over the questions. An interview guide, including the aim and purpose of the interview as well as contact details of the interviewer, is preferable should there be any questions (Table 3). Together with the guide, the interview questions should be made available so that the interviewee can prepare his or her answers properly in order to get the best results out of the interview. 
Table 3 Interview questions to representatives from design regarding information received from manufacturing, service, remanufacturing and other stakeholders, respectively

Questions to stakeholders

\begin{tabular}{ll}
\hline Subject & Questions \\
\hline $\begin{array}{l}\text { Information from manufacturing, } \\
\text { service and remanufacturing and }\end{array}$ & $\begin{array}{l}\text { 1. What information does design receive from manufacturing, } \\
\text { other stakeholders, respectively }\end{array}$ \\
& service, remanufacturing and other stakeholders? \\
& 1.2 How is that information transferred (channel/system) \\
& 1.2 .1 When in the design process is that information used? \\
& 1.3 What information is the most important? \\
& 1.4 Is there information that is not used? \\
& 1.4 .1 If so, why is that information not used? \\
& 1.5 What other information could be useful for design? \\
& 2. How are the decisions taken in the design phase? \\
& 2.1 What criteria go into the design process? \\
& 2.2 What laws and regulations must be considered when \\
designing the product? & 2.2 What requirements does design have to include regarding \\
Decisions and requirements & end-of-use aspects (e.g., remanufacturing)? \\
& 2.3 What are the entities of the requirements specification relevant \\
to remanufacturing?
\end{tabular}

During the interview, follow-up questions and questions that will clarify the responses are required. This semi-structured approach will contain interview questions that will vary from interview to interview and thus are not specified. A preferable approach for performing these interviews is to illustrate the information flows on, e.g., a whiteboard while the interview is carried out. Thus, as a stakeholder is brought up in the interview, the name of that stakeholder is also written down on the whiteboard. Likewise, as the information flows are described, lines will be drawn between the stakeholders to illustrate the information exchange.

The intention of this step is to capture the actual situation in a way that is illustrative of the reality. This might bring clarity to the current situation, and not only to the interviewer but also to the interviewee. The illustration can then be used as a communication tool when merged with the answers of the other relevant interviewees. Each profession will have its angle of the complex system that is information sharing within an organisation. It is, however, very important that the interviewee gets an opportunity to verify his or her answers. Hence, at the end of each interview, the interviewer summarises the interview by reading the answers to the interview questions and letting the interviewee verify, add to or correct the answers.

After all the interviews have been carried out, they need to be analysed. The analysis is conducted by drawing up information flows (see Fig. 3). More stakeholders than those interviewed will be in the illustration. It could be valuable to interview them as well to get a richer picture; however, the responses from the four stakeholders design, manufacturing, service and remanufacturing are enough to get a sufficient picture of the current situation. Indeed, the feedback transfer between remanufacturing and design might be very different from how feedback is transferred from manufacturing and design. However, all information transfer found in the interviews should be included in the final illustration. Although remanufacturing may not provide feedback to design, remanufacturing needs to be included 


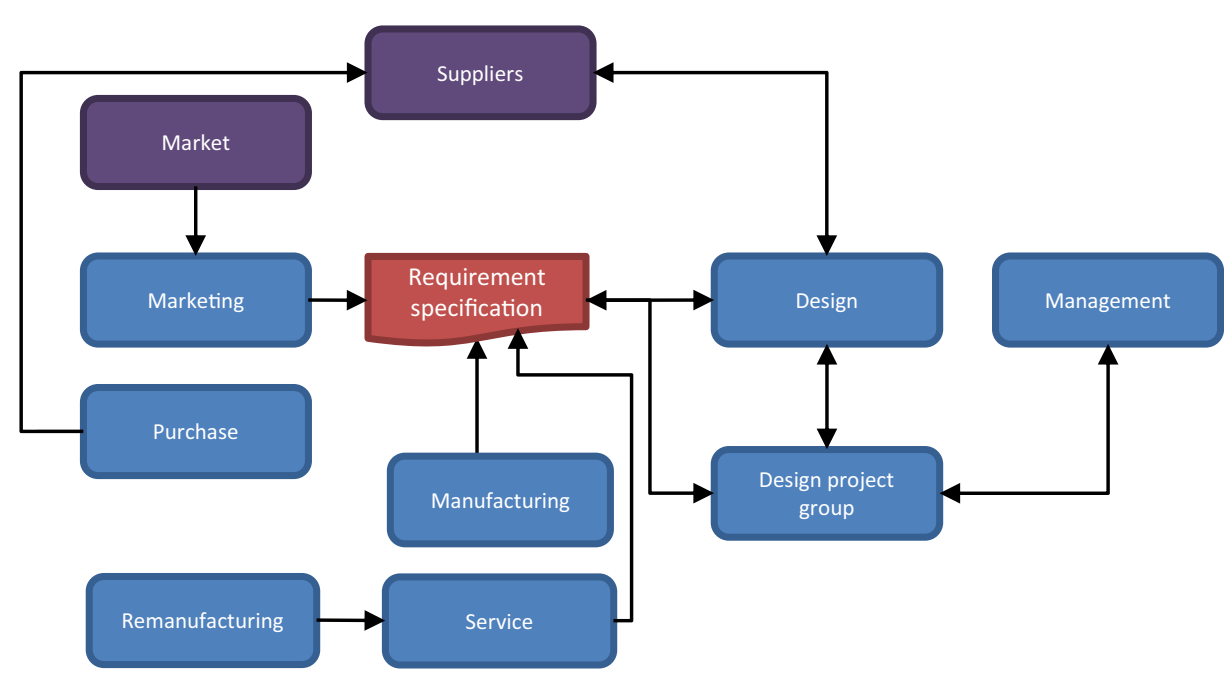

Fig. 3 The information flows among the stakeholders in the design projects at the case company. The internal stakeholders are marked in blue, the external stakeholders represented in purple. In the centre of the illustration is the design requirement specification, where all product requirements are stated. This document guides the entire product development process

as one of the stakeholders in the final illustration. Thus, when setting up the illustration of the information flows, start by placing design, manufacturing, service and remanufacturing.

If carried out correctly, the assessment of the current state should be disseminated throughout the organisation, and areas for improvement clearly pointed out. Often, the situation is not clear until the illustration is complete, and it is easier to compare and contrast remanufacturing's involvement in the feedback transfer than if only remanufacturing and design were interviewed. Preferably, areas for improvement should be discussed, clarified and summarised in a document.

\section{Step 2 - Outline future vision}

When the current situation is mapped, analysed and communicated, the next step is to identify a vision of a desirable scenario: in other words, what the ideal scenario looks like concerning how feedback from remanufacturing should reach design and be integrated into the design process. This scenario should be outlined by a team of representatives from design, remanufacturing and top management. What the desired future vision is will be company dependent; however, it should specify a principle-based scenario for optimal feedback transfer from remanufacturing to design.

When the initial mapping of the current stage and a clear vision has been established, there will be a gap between the current state and the vision. That gap is addressed in this framework by implementing feedback actions such as (presented in order of complexity):

- Genchi gembutsu ("go see"), where the product designers visit the remanufacturers to learn about the remanufacturing process and specific issues. 
- Feedback from technicians in the remanufacturing facility, e.g., collected via a software application or a "know-how" database.

- Wear on components from visual inspection, measurements, and/or condition monitoring.

- Workshops/integration events, where remanufacturing staff and product designers meet to learn from each other and solve problems.

- An ombudsman for remanufacturing, appointed to speak for the remanufacturer in the product development projects.

- A fully integrated product development process with cross-functional teams, including remanufacturing represented as one of the stakeholders and value providers in the value chain.

These examples of actions are suggested based on findings in empirical studies and the lean product development literature [see, e.g., 19, 26, 30, 42]. The idea is that once the current stage and vision are clarified, different strategies for integrating feedback into the product design process should be discussed. The actions should be chosen based on the level of appropriateness for the specific case company. It should be pointed out, however, that not all these actions need to be taken; the best combination is to be decided by each company based on its assessed current state and outlined future vision.

In order to reach the desired vision outlined in Step 2, the actions are prioritized and specified in a time plan that will also include evaluations after each implementation action. Thus, when promising actions have been chosen, they should be ranked according to how easy they are to implement, then prioritized. Initially, easily implementable actions should be adopted. It is better to start taking actions in the aimed direction than to do nothing and wait for major changes if the different actions are not heavily interdependent. The actions will then be implemented stepwise, where the actions are implemented and evaluated after a fixed period of time. What is seen as an easy strategy or a difficult one will depend on the specific company.

\section{Step 3 - Implement feedback actions}

The planned actions are now to be implemented. The stakeholders will participate in the actions, and the goal is that design will not only receive feedback from remanufacturing but also get knowledge about the remanufacturing process and use the information and knowledge in the design process. For instance, if Genchi gembutsu is applied, the designers will visit the remanufacturers to learn about the remanufacturing process and specific issues. During the visit, they can ask questions and get information about the used products and components first-hand. They can also get a demonstration of how certain parts are disassembled and see with their own eyes how design features affect the remanufacturing process.

In the process of working with implementing the actions, the achieved information and knowledge need to be captured. Such documentation is, for instance, design support such as design checklists (see Table 5), guidelines and "know-how" sheets. Other documentation methods such as A3 reports [36] (where all improvement work information is written down and illustrated) and other intra-organizational documents will support the process of upholding the actions and continuous improvements. 
When the actions have been implemented and at a certain time interval (e.g., six months), an evaluation follows. The evaluation will take place before the next implementation phase begins, and so on until the goal is reached.

\section{Step 4 - Evaluate current feedback and future vision}

The evaluation phase consists of two parts. The first evaluation and success criteria will indicate whether or not the actions increase of information feedback from remanufacturing to design has led to DfRem. Here, a DfRem checklist could be used to verify the actions that have taken place during the implementation phase (Step 3) in order to achieve DfRem. Examples of design criteria for DfRem are listed below:

- Use of standardized parts

- Robust material selections

- Modular design

- Upgradeability

- Assembly methods that allow for non-destructive disassembly and reassembly

- Minimal number of connectors

- Reusable connectors

- Easy access to wear and tear parts

- Shapes that are suitable for cleaning

- Materials that are easy to clean

- Corrosion-resistant parts

- Timeless design

Hence, the provided checklist should be filled in to verify what components were modified and to meet the requirements from remanufacturing. For instance, the component thickness may have been increased to allow for the reprocessing of goods (e.g., the grinding of engine parts), or a more durable material may have been used on a critical component to prolong its predicted lifetime (e.g., metal instead of plastic). Thus, the outcome of the work with improved feedback strategies can be monitored, and the progress documented after each feedback action implemented. In order to monitor the progress and DfRem design change achievements, spider charts are used. The initial design is assessed, and then the following evaluation of DfRem design achievements is added to the chart. Thus, the results of the evaluation can be illustrated, and the progress more easily observed.

The second part of the evaluation is an assessment of how the implementation of feedback from the remanufacturers proceeded, i.e., whether the implementation occurred as planned and what unforeseen factors may have influenced the outcome. In this stage, it is also relevant to re-evaluate the implementation plan. Since companies operate in a changing environment, it is possible that the vision and/or implementation plan must be revised. Alterations of the market, such as the financial situation, technology developments or intra-organisational restructures, may impact the plan. Hence, this part of the evaluation step adds a dynamic element to the framework. The main reason for this dynamic part is that the framework need not be discarded even though external or internal factors may interfere with the initial action plans. As the evaluation is complete, the implementation will continue with the next action until the results are aligned with the desired vision. Continuous improvement should then be applied. 


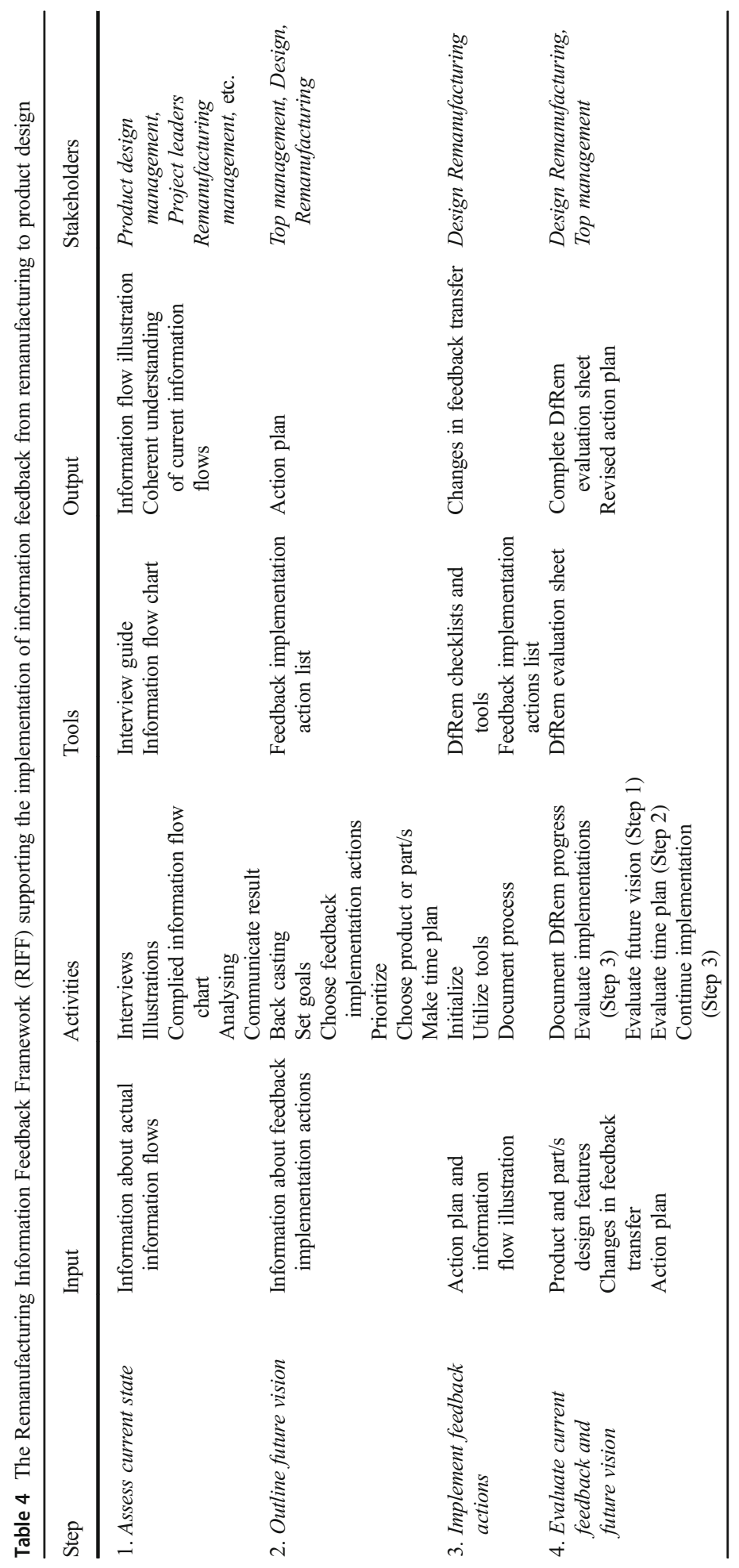


The contents of the framework are presented in a condensed form below (Table 4). The table shows the steps of the framework with associated input to the required activities. Further, the tools provided in the framework are listed, and the expected resulting output presented. Finally, the primary stakeholders involved in the respective steps are presented.

This framework has been initialised at a case company. The characteristics of the case company and the outcomes of the initialisation are presented below.

\section{Case study at an OEM of electro-mechanical machines}

The proposed framework has been initialised at a case company in Sweden.

\section{Case company characteristics}

The case company designs, manufactures and sells complex electro-mechanical machines. The company has been established for 75 years, and the remanufacturing process has been active for the past 15 years. The majority of its machines, about $75 \%$, are leased. The machines are leased on a short or long-term basis, varying from one day up to five years. The company engaged in remanufacturing in order to manage the return flow of leased products as remanufacturing enables the same machines to be leased several times. Remanufacturing takes place both between leasing contracts and before the machines are sold as remanufactured products. The leasing of machines has expanded over the years and is a major part of the company's turnover. The newly manufactured machines are often leased and then remanufactured a couple of times before they are sold as used goods or scrapped. Although remanufacturing is a vital part of the company's business plan, remanufacturing is not a part of the sales strategy. Remanufacturing struggles to be acknowledged in the organisation. However, remanufacturing sales did not drop during the economic recessions that Europe experienced, opposite to the decline in sales of new machines.

Organisationally, the company consists of two main entities: a producing facility and a sales organisation. Design and manufacturing are included in the producing unit, while service and remanufacturing are included in the sales organisation. This organisational structure affects decisions made in, for instance, the design phase. When a new product is planned for, the budget is foremost based on the cost of producing the product, including the development cost, while the total life-cycle cost is not considered. The company is applying lean principles in the organisation, and recently this has also included design. The product is fairly complex and available in many models and customized variants. Although the product is robust, it is still not designed for remanufacturing. A reason for this could be that remanufacturing is a rather new activity that started 10-20 years ago, while manufacturing has been ongoing since the company started. Another reason could be that remanufacturing is an activity that occurs in the sales companies, while design and manufacturing occur in the product company.

\section{Step 1 - assess current state}

When the machines are designed, consideration is taken foremost for the final customer and end user, but service and manufacturing aspects are also included in the requirement specification documents. The product development process is relatively newly defined as an integrated development process, including manufacturing feedback already in the early phases. 
Service also has representatives in the product development projects who contribute with their points of view. It also uses expert representatives from amongst the service technicians working in the field as sources of information that it can then bring in to the new product development projects. The service technicians receive information about problems with the machines first-hand. They also establish good contact with the end customer, learning about their business and application of the machines.

Information feedback from the service technicians in the field is communicated to design via the marketing department. Service technicians, in turn, receive information feedback from the customers when they perform service in the field. In service meetings that are held at least once a year at the customer's site, service questions the customer about their satisfaction with the service, machines, and how frequently they use them and makes sure that the customer follows the terms in the leasing contract. Service sometimes participates in pre-delivery inspections at the customer's site and thus sees first-hand how the machines are used.

Tasks concerning quality and suggestions for improvements (related, for instance, to service-related costs caused by low quality) are communicated to service via the quality department. On occasion, service provides feedback to manufacturing if malfunctions are frequently discovered. Manufacturing receives information about problems with the machines in use from the market via the quality department. Remanufacturing rarely receives information from the service technicians about aberrations, and if it does, it depends on the individual, not on a system of information exchange.

An overview of the information flows in the case company is illustrated in Fig. 3. The figure includes information flows to and from the departments of design, manufacturing, service and remanufacturing. As seen in the figure, remanufacturing is separated from design organisation-wise and a lack a connection via feedback.

\section{Step 2 - outline future vision}

A team consisting of the design manager, a product owner from design, a designer, the environmental manager, an environmental engineer and the remanufacturing manager was brought together to discuss the current situation of lack of feedback transfer from remanufacturing to design. The result of Step 1 was presented and verified by the involved parties.

Recent changes in the company have a potential impact on the possibilities for the current situation to change regarding establishing feedback from remanufacturing to design. In fact, the case company has identified that close communication between design and remanufacturing is a key factor for the success of their circular business model. The company now has a focus on the circular economy, and used products have become a strategically valuable product, as well as brought up as an environmentally beneficial activity within the company. The first action towards integrating information feedback is to let the designers go and see the remanufacturing process with their own eyes, i.e., according to the Genchi gembutsu principle. This action is easy to implement as the lean philosophy adopted by the case company, and it requires no major changes in the design process.

Knowledge about remanufacturing in other departments of the company is often poor, and there is little structured interaction with remanufacturing. Nevertheless, a few teams of designers, including the chassis design team, visited the remanufacturing facility last year. These sorts of activities need only planning and to structure future continuance involving all design teams. In addition, the remanufacturing manager and the environmental manager suggest that all module 
owners from the design teams meet at the remanufacturer to discuss DfRem problems and solutions. Further, they suggest that managers from departments in the company meet at remanufacturing for a workshop to discuss leadership concerning remanufacturing. Thus, action number two to be implemented is workshops and integration events.

The remanufacturing staff have identified product design improvements that could be profitable for the company - for instance, fewer variants of engines and fewer variants of the machines. Today, the many variants of machines and parts are counterproductive for efficient remanufacturing and increase the cost for remanufacturing. Likewise, customized products are not as easy to remanufacture since they have to be redesigned, and thus most often are not remanufacturable. Further, remanufacturing acknowledges that a more mature modular design would benefit remanufacturing.

A bottleneck hindering DfRem is that remanufacturing is not considered in the product planning process, nor the design process. However, the remanufacturing manager states that establishing feedback channels has the potential to make remanufacturing more efficient and to work as a sales argument for more sustainable products. Currently, design requirements from service come via a central part of the organization to product planning. The remanufacturing manager suggests utilising the same channel for design requirements and feedback from remanufacturing as it is an established channel. Thus, action number three is preferably to implement feedback from remanufacturing technicians.

As the company has started to integrate service more and more in the design process and coupled with the increased number of leased products that need remanufacturing, the threshold for also integrating remanufacturing in the future might be lower. However, remanufacturing does not benefit from being grouped with service. Previously, it did not have use for software designed for service. Now, it finally has software designed for remanufacturing needs.

In short, the future vision for the case company is:

- Communication between design and remanufacturing identified as a key factor for the success of their circular business model

- "Go see" practices are routine

- Feedback channel existing for feedback from service could be used for feedback from remanufacturing as well

- Increased modular design

- Remanufacturing considered in product planning

- DfRem included in product requirements specification

\section{Step 3 - implement feedback actions}

In short, the current state at the company is:

- Study visits initialised

- "Go see" practices initialised

- Feedback barriers evident

- Poor knowledge of remanufacturing

- Critical component for DfRem identified

- $50 \%$ of machines scrapped

- $\quad$ Lack of legislation pushing for more sustainable machines of this kind 
The company has started to implement "go see" practices. Design engineers are now visiting the remanufacturing facility occasionally to observe in person how the machines have been worn, and not only consult service breakdown figures. Further, feedback from the remanufacturing technicians who inspect the machines and evaluate what in the machine is reusable is considered very important to prolong the lifetime of the machines. As the machines continue to provide value as long as they can be rented and remanufactured again, this is a key factor for the OEM. However, it is also important that the sales department, as well as the sustainability department, realises the potential of remanufacturing and circular material flows so that everyone is pulling in the same direction. In order to utilize the full potential of the circular business model, it is important to design a system that allows for efficiency even after the initial use phase. According to the environmental manager, it is important that the system allows for the remanufacturing of the entire product as a first option, and ultimately is cannibalized and sold as a second-hand product. Further, the workshops where representatives from design, manufacturing, service, sustainability and remanufacturing have met have had an impact on the work that is now taking place. Recently, the company has recognised remanufacturing as an important strategy for sustainability as the circular economy is becoming important on the agenda for business, and they highlight that their own circularity was implemented years before the term was established. Previously, customers only asked for recyclability, and that is also what the sustainability reports illustrate. The machines already have a recycling rate of $99 \%$; however, the reuse of components in remanufactured products could be another factor to consider in the future.

The company has no real numbers of what cost savings could be gained with remanufacturing, nor what future profits DfRem might generate. However, one critical part of the machine is a supporting frame; if that frame has to be exchanged, the cost of replacing the old one with a new is more than the entire machine. Thus, if the frame cannot be remanufactured, remanufacturing is not economically feasible. Today, the frame is often a problem for the remanufacturer. Furthermore, roughly $50 \%$ of the machines that come to the remanufacturing centre are scrapped partly based on quality and lifetime, and partly because there are many machines which are customized due to high demand for products adapted for the constraints at the customers' sites. However, customized machines are not entirely useful for remanufacturing, as remanufacturing large quantities of products entails standardized products built to the original specification, according to the remanufacturing manager.

There is a need to communicate from the top down in the organization if remanufacturing is to be prioritized. The management of the company requests a low-cost product. The group sees remanufacturing as an important player to engage in order to meet that need. The implementation of the feedback activities is yet to be carried out in full scale. The potential for the framework is promising; however, the work needs to be carried out completely by the case company before any conclusions can be made.

\section{Step 4 - evaluate current feedback and future vision}

In order to monitor the progress in improved feedback from remanufacturing to design and its expected impact in DfRem design changes, the evaluation sheets from each evaluation will be stored. Thus, as a new evaluation is carried out the progress between the previous reviews and the current can be observed. An example of an evaluation sheet is shown in Table 5. 
Table 5 An extract from an evaluation sheet where DfRem design changes are marked with an X. Each chosen component or module will be evaluated on all DfRem criteria (adapted from [29])

\begin{tabular}{|c|c|c|c|c|c|}
\hline \multicolumn{2}{|c|}{$\begin{array}{l}\text { Date: } 2019-01-20 \\
\text { Last review: } 2019-01-24\end{array}$} & \multirow{2}{*}{$\begin{array}{l}\text { Product: } \\
\text { Machine XM } \\
\text { Component/Module }\end{array}$} & \multicolumn{3}{|c|}{ Responsible: Linda Nordlund } \\
\hline $\mathrm{Nr}$ & Design for Remanufacturing criteria & & Achieved & $\begin{array}{l}\text { Partly } \\
\text { achieved }\end{array}$ & $\begin{array}{l}\text { Not } \\
\text { achieved }\end{array}$ \\
\hline 1 & Use of standardized parts & Frame & & $\mathrm{X}$ & \\
\hline 2 & Robust material selections & Frame & $\mathrm{X}$ & & \\
\hline 3 & Modular design & Frame & & $\mathrm{X}$ & \\
\hline 4 & Upgradeability & Frame & & $\mathrm{X}$ & \\
\hline 5 & $\begin{array}{l}\text { Assembly methods that allow for non-destructive } \\
\text { disassembly and reassembly }\end{array}$ & Frame & & & $X$ \\
\hline 6 & Minimal number of connectors & Frame & & $\mathrm{X}$ & \\
\hline 7 & Reusable connectors & Frame & & & $\mathrm{X}$ \\
\hline 8 & Easy access to short-lived parts & Frame & & & $\mathrm{X}$ \\
\hline 9 & Shapes that do not prevent cleaning & Frame & & $\mathrm{X}$ & \\
\hline 10 & Materials that are easy to clean & Frame & $\mathrm{X}$ & & \\
\hline 11 & Corrosion resistant parts & Frame & $\mathrm{X}$ & & \\
\hline 12 & Timeless design & Frame & & $X$ & \\
\hline
\end{tabular}

Currently, the case company is implementing "go see" practices; however, the outcomes of Step 3 are yet to be evaluated. This will be an ongoing process that needs continuous improvement and evaluation according to the RIFF - Step 4.

\section{Discussion}

The novelty of this paper is that it provides a framework (The RIFF framework presented in Section 4) which addresses the gap between the DfRem methods available and their lack of use in industry. Previous research has identified available information feedback from remanufacturing to design, as well as the lack of transfer of such feedback (e.g., [22, 27]). Other researchers have also pointed out the lack of communication between the OEM and the remanufacturer as influencing the DfRem integration into the design process [i.e., 17]. Indeed, Hatcher et al. [18] point out three success factors for the integration of DfRem into the design process: management commitment, designer motivation, and designer knowledge and understanding. In order to integrate information feedback into the design process, the DfRem method proposes addressing all of these factors. It is not suggested that, e.g., educating designers about remanufacturing would be enough to get DfRem aspects integrated into the design process, but rather that it is an initial step of understanding remanufacturing and a stepwise transition into a more complete alteration of the way the organisation could tackle DfRem in the future. Further, the Remanufacturing Decision-Making Framework (RDMF) by Subramoniam et al. [38] highlights the importance of designing a product for remanufacturing and proposes the action "Work with the OE division to design for remanufacturing". However, the RDMF does not support how to implement DfRem, and hence, the RIFF method could be utilized as a compliment to the RDMF and thus facilitate companies that want to remanufacture their products. However, the RIFF method is not limited for use at companies that would like to start up remanufacturing 
but could also support the improvement of an already existing remanufacturing process, as illustrated in the case description.

The proposed framework aims, at a strategic level, to support companies regarding the integration of information feedback into the design process. The method was initiated at a case company in Sweden that showed good potential for improving the feedback flows from remanufacturing to design. The information flows regarding the product development process were mapped through interviews, and the result was presented in an illustration showing that remanufacturing is mostly disregarded in the product development process. The actions for improving feedback transfer were presented and well received. However, the framework has not been completed in the case company, as the evaluation step is not carried out. This is due to the circumstantial procedures for engaging in a project of this scale. Recent managerial objectives point in a positive direction, and the progress will be monitored in future research.

In lean product development, organizational learning supported by information creation, processing and sharing within and across companies is one of the most important factors in pursuing competitive advantage and designing good products [25]. In the core of the proposed framework are practical actions for change and learning across an organisation, inspired by the lean product development philosophy [e.g., 26]. These start with the visualisation of the information flows in the design process, aimed at compiling and spreading knowledge about the prevailing information transfer. In lean product development, visualisation methods are used with the same purpose [30].

Further, the actions for implementing feedback from remanufacturing to design promote learning and include communication within the organisation. For instance, the use of cross-functional teams provides information and helps to develop alternative design concepts [42]. Additionally, Kurilova-Palisaitiene [21] advocates the use of cross-functional teams to address weak collaboration, information exchange, and miscommunication within the organisation, which causes prolonged lead times in the remanufacturing process. Furthermore, the Ombudsman's role is to communicate information and his/her knowledge about remanufacturing and the company-specific remanufacturing process to the product development project team. Thus, the Ombudsman's role has similarities with a chief engineer in lean product development, as he or she transfers tacit knowledge about the customer to explicit knowledge to the design engineers [30]. Objective information can be gathered via condition monitoring and other smart technologies to gain deeper insights about the cores to be remanufactured [32]. This information can be feedback to design for further insights.

On a practical level, there are tools pointing out how to design for remanufacturing, e.g., DfRem checklists and guidelines [e.g., 15]. The proposed framework encourages the use of such tools by integrating a DfRem checklist as an evaluation tool. Thus, documentation is created to avoid the uncertainty of the improvement progress. However, the exact design approach is left for the individual company to identify, as all products and companies are unique. Nevertheless, DfRem should be planned for in the early phases of the design process in order to be efficient [33]. Continuous improvements are proposed as an important component of the framework, and they are a key element of organizational learning [26].

Thus, the proposed framework provides holistic support for integration of DfRem into the design process via the use of information feedback from the remanufacturers. Hence, its goal is to support knowledge and understanding of the company-specific remanufacturing process, as well as to refine ongoing DfRem activities. Similar approaches considering feedback as a 
valuable input can be found in other DfX methods (e.g., the design for manufacturing (DfM) approach [20]) and might be the next step in defining a more strategic aspect of DfRem.

As more products are designed for remanufacturing, the remanufacturing process will be more efficient. Further, this implies that as more products are remanufactured, sustainable circular product flows and the circular economy are reinforced.

\section{Conclusions}

The aim of this paper was to present a Remanufacturing Information Feedback Framework that supports design for remanufacturing by the implementation of feedback from remanufacturing to design. The proposed framework is directed at OEMs that include or have control over both the design and remanufacture of their products. The framework, described in Section 4, was developed based on years of research and collaboration with the case company as well as on previous research on how models aimed at product designers should be developed and theory of design for remanufacturing, information integration in the product development process and lean product development practices.

The framework is based on an initial evaluation of the current information feedback transferred from remanufacturing to design, as well as setting the vision for what the feedback should look like in the future. The core of the framework consists of a stepwise implementation process of information feedback actions and strategies from remanufacturing to design and is distinguished by evaluation between each implementation step. These evaluations verify the progress of the implementation as well as allow for alterations of the implementation phases to come, as external influences (such as the market situation) may alter the planned implementation.

The framework in its current stage has yet to be fully implemented and verified. Whether there is a possibility to expand on the framework and improvements to be made is the scope of future research.

Acknowledgements The authors wish to acknowledge the Swedish innovation agency VINNOVA, the Swedish Governmental Innovation Agency, for financing the case study research. This research also has funding from the Mistra REES (Resource-Efficient and Effective Solutions) program, funded by Mistra (The Swedish Foundation for Strategic Environmental Research) (grant number DIA 2014/16) and funding from the European Union's Horizon 2020 research and innovation programme under grant agreement No 776851 within the project called CarE-Service. The authors would also like to acknowledge the participating respondents from the case company for their contribution.

Funding Information Open access funding provided by Linköping University.

Abbreviations $D f A$, Design for Assembly; $D f D$, Design for Disassembly; $D f M$, Design for Manufacturing; $D f R e m$, Design for Remanufacturing; EoL, End of Life; EoU, End of Use; OEM, Original Equipment Manufacturer.

Open Access This article is distributed under the terms of the Creative Commons Attribution 4.0 International License (http://creativecommons.org/licenses/by/4.0/), which permits unrestricted use, distribution, and reproduction in any medium, provided you give appropriate credit to the original author(s) and the source, provide a link to the Creative Commons license, and indicate if changes were made. 


\section{References}

1. Abramovici, M.; Lindner A. (2011) Providing product use knowledge for the design of improved product generations. CIRP Ann., 60, 211-214.

2. Abramovici, M.; Neubach, M.; Fathi, M.; Holland, A. (2009) Knowledge-based feedback of product use information into product development. In Proceedings of the 17th International Conference on Engineering Design Information and Knowledge, Palo Alto, CA, USA, 24-27 August 2009; pp. 227-238.

3. Allwood JM, Ashby MF, Gutowski TG, Worrell E (2011) Material efficiency: a white paper. Resour Conserv Recycl 55(3):362-381

4. Amezquita, T., Hammond, R., Bras, B. (1995). Characterizing the remanufacturability of engineering systems. In: ASME advances in design automation conference, DE-vol. 82. ASME, Boston, Massachusetts p. 271-278

5. Bogue R (2007) Design for disassembly: a critical twenty-first century discipline. Assem Autom 27:285289

6. Boothroyd G, Dewhurst P (1986) Product Design for Assembly. Boothroyd Dewhurst Inc., Wakefield

7. Bras B. and Hammond R. (1996). Towards Design for Remanufacturing: metrics for assessing remanufacturing, proceedings of the 1 st international workshop on reuse

8. Charter M, Gray C (2008) Remanufacturing and product design. Int J Prod Dev 6(3-4):375-392

9. Dienst, S.; Fathi, M.; Abramovici, M.; Linder, A. (2011) A conceptual data management model of a feedback assistance system to support product improvement. In Proceedings of the IEEE International Conference Systems, Man, and Cybernetics (SMC), Anchorage, AK, USA, 9-12 October 2011; pp. 446451.

10. Doyle K (2011) Investigating the requirements needed to make appropriate end of life decisions. In Proceedings of the 18th International Conference on Engineering Design (ICED 11), Impacting Society through Engineering Design. Copenhagen, Denmark

11. Elo K, Sundin E (2014) Concepts for a semi-automatic dismantling process of LCD television sets. Procedia CIRP 23:270-275

12. Fathi, M.; Holland, A.(2009). Knowledgebased feedback integration to facilitate sustainable product innovation. In Proceedings of the ETFA, IEEE Conference on Emerging Technologies and Factory Automation, Palma, Spain, 22-25 September 2009.

13. Harjula T, Rapoza B, Knight WA, Boothroyd G (1996) Design for Disassembly and the environment. Ann CIRP 45:109-114

14. Hatcher, G. D. (2013). Integrating Design for Remanufacture into the Design Process: The Operational Factors. PhD Thesis. University of Strathclyde, Glasgow, UK

15. Hatcher GD, Ijomah WL, Windmill JFC (2011) Design for remanufacture: a literature review and future research needs. J Clean Prod 19(17-18):2004-2014

16. Hatcher, G.D., Ijomah, W.L. \& Windmill, J.F. (2013). Design for remanufacturing in China: a case study of electrical and electronic equipment. Jnl Remanufactur (2013) 3(1):3. https://doi.org/10.1186/2210-4690-3-3

17. Hatcher GD, Ijomah WL, Windmill JFC (2014) A network model to assist 'design for remanufacture' integration into the design process. Journal of Cleaner Production 64:244-253 ISSN 0959-6526

18. Ijomah WL, McMahon CA, Hammond GP, Newman ST (2007) Development of robust design-forremanufacturing guidelines to further the aims of sustainable development. Int J Prod Res 45(18 \& 19): 4513-4536

19. Khan MS, Al-Ashaab A, Shehab E, Haque B, Ewers P, Sorli M, Sopelana A (2013) Towards lean product and process development. Int J Comput Integr Manuf 26(12):1105-1116

20. Kuo T-C, Huang SH, Zhang H-C (2001) Design for manufacture and design for X: concepts, applications and perspectives. Comput Ind Eng 41:241-260

21. Kurilova-Palisaitiene, J. (2018). Lean Remanufacturing: Reducing Process Lead Time. PhD Thesis Linköping University, Sweden https://doi.org/10.3384/diss.diva-147875

22. Kurilova-Palisaitiene J, Lindkvist L, Sundin E (2015) Towards facilitating circular product life-cycle information flow via remanufacturing. Procedia CIRP 29:780-785 ISSN 2212-8271

23. Lee, H.M. (2008). An ontology-based product design adviser for assessing end-of-life (EoL) performance. Electrical and Electronic Engineering. Singapore, Nanyang Technological University

24. Lee, J.; Ni, J.; Djurdjanovic, D.; Qiu, H.; Liao, H. (2006). Intelligent prognostics tools and e-maintenance. Comput. Ind., 57, 476-489.

25. León HCM, Farris JA (2011) Lean product development research: current state and future directions. Eng Manag J 23(1):29-51

26. Liker JK, Morgan JM (2006) The Toyota way in services: the case of lean product development. Acad Manag Perspect 20(2):5-20 
27. Lindkvist L, Sundin E (2012) Life-cycle information feedback to product design. Proceedings of the Swedish Production Symposium Linköping, Sweden, pp 99-105

28. Lindkvist Haziri L., Sundin E. and Sakao T. (2019) Feedback from Remanufacturing: Its Unexploited Potential to Improve Future Product Design, Sustainability, 11, 4037. https://doi.org/10.3390/su11154037

29. Lindkvist, L., and Sundin, E. (2016). A stepwise method towards products adapted for remanufacturing. Proceedings of the DESIGN 2016 14th international design conference, Dubrovnik, Croatia, pp. 321-330

30. Lindlöf L, Söderberg B, Persson M (2013) Practices supporting knowledge transfer-an analysis of lean product development. Int J Comput Integr Manuf 26(12):1128-1135

31. Mangun D, Thurston D (2002) Incorporating component reuse, remanufacturing and recycle into product portfolio design. IEEE Trans Eng Manag 49:479-490

32. Ondemir O, Gupta SM (2014) Quality management in product recovery using the internet of things: an optimization approach. Comput Ind 65(3):491-504

33. Pozo Arcos B., Balkenende A.R., Bakker C.A. and Sundin E. (2018). Product Design for a Circular Economy: Functional Recovery on Focus, In DS 92: Proceedings of the DESIGN 2018 15th International Design Conference, pp 2727-2738. https://doi.org/10.21278/idc.2018.0214

34. Prendeville, S. and Bocken N. (2017). Design for remanufacturing and circular business models. Sustainability Through Innovation in Product Life Cycle Design. Springer, Singapore, 269-283

35. Rose C, Ishii K (1999) Product end-of-life strategy categorisation design tool. J Electron Manuf 9:41-51

36. Chakravorty SS (2009) Process improvement: using Toyota's A3 reports. Qual Manag J 16(4):7-26. https://doi.org/10.1080/10686967.2009.11918247

37. Steinhilper R (1998) Remanufacturing - the ultimate form of recycling. Fraunhofer IRB Verlag, Stuttgart

38. Subramoniam R, Huisingh D, Chinnam RB (2010) Aftermarket remanufacturing strategic planning decision-making framework: theory \& practice. J Clean Prod 18(16-17):1575-1586

39. Sundin E, Bras B (2005) Making functional sales environmentally and economically beneficial through product remanufacturing. J Clean Prod 13(9):913-925

40. Sundin E and Lee H.M. (2011). In what way is remanufacturing good for the environment? Proceedings of the 7th international symposium on environmentally conscious design and inverse manufacturing (EcoDesign-11), ISBN: 978-94-007-3010-6, November 30 - December 2, Kyoto, Japan, pp 551-556

41. Sundin E, Lindahl M (2008) Rethinking product Design for Remanufacturing to facilitate integrated product service offerings, proceedings of IEEE international symposium on electronics and the environment (IEEE08). USA, San Francisco

42. Tyagi S, Cai X, Yang K, Chambers T (2015) Lean tools and methods to support efficient knowledge creation. Int J Inf Manag 35(2):204-214

43. Xu, D.F.; Li, Q.; Jun, H.-B.; Browne, J.; Chen, Y.L.; Kiritsis, D. (2009) Modelling for product information tracking and feedback via wireless technology in closed-loop supply chains. Int. J. Comput. Integr. Manuf. 2009, 22, 648-670.

44. Yang SS, Ong SK, Nee AYC (2015) Towards implementation of DfRem into the product development process. Procedia CIRP 26:565-570 ISSN 2212-8271

45. Zhang, D.; Hu, D.; Xu, Y.; Zhang, H. (2012) A framework for design knowledge management and reuse for Product-Service Systems in construction machinery industry. Comput. Ind. 2012, 63, 328-337.

Publisher's note Springer Nature remains neutral with regard to jurisdictional claims in published maps and institutional affiliations. 